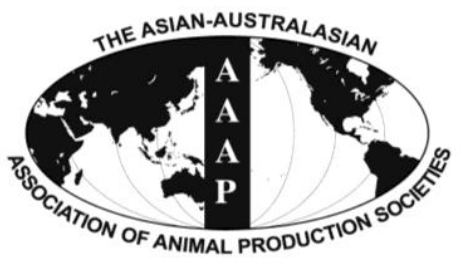

Asian-Aust. J. Anim. Sci.

Vol. 25, No. $10: 1473$ - 1480

October 2012

www.ajas.info

http://dx.doi.org/10.5713/ajas.2012.12146

\title{
Porcine Knock-in Fibroblasts Expressing hDAF on $\alpha-1,3-$ Galactosyltransferase (GGTA1) Gene Locus
}

\author{
Ji Woo Kim, Hye-Min Kim, Sang Mi Lee and Man-Jong Kang* \\ Department of Animal Science, College of Agriculture and Life Science, \\ Chonnam National University, Gwangju, 500-757, Korea
}

\begin{abstract}
The Galactose- $\alpha 1,3$-galactose $(\alpha 1,3 \mathrm{Gal})$ epitope is responsible for hyperacute rejection in pig-to-human xenotransplantation. Human decay-accelerating factor (hDAF) is a cell surface regulatory protein that serves as a complement inhibitor to protect self cells from complement attack. The generation of $\alpha 1,3$-galactosyltransferase (GGTA1) knock-out pigs expressing DAF is a necessary step for their use as organ donors for humans. In this study, we established GGTA1 knock-out cell lines expressing DAF from pig ear fibroblasts for somatic cell nuclear transfer. hDAF expression was detected in hDAF knock-in heterozygous cells, but not in normal pig cells. Expression of the GGTA1 gene was lower in the knock-in heterozygous cell line compared to the normal pig cell. Knock-in heterozygous cells afforded more effective protection against cytotoxicity with human serum than with GGTA1 knock-out heterozygous and control cells. These cell lines may be used in the production of GGTA1 knock-out and DAF expression pigs for xenotransplantation. (Key Words: Gene Targeting, Pig Fibroblasts, Xenotransplantation, Knock-out, Hyperacute Rejection)
\end{abstract}

\section{INTRODUCTION}

The acute shortage of donated human organs for clinical transplantation has led to the study of animal organs for xenotransplantation (Ye et al., 1994; Sprangers et al., 2008). Pigs are ideal xenograft donors because their organs are physically and physiologically suited for transplantation into humans (Ye et al., 1994; Sprangers et al., 2008). In pigto-human xenotransplantation, the most important barrier is immunological rejection of the organ graft (Yang and Sykes, 2007; Sprangers et al., 2008). The rejection of the grafted organ in pig-to-human xenotranplantation by cascades of immune mechanisms can be classified as hyperacute rejection (HAR), acute humoral xenograft rejection (AHXR), immune cell mediated rejection, and chronic rejection (Yang and Sykes, 2007; Le Bas-Bernardet et al., 2008).

A major barrier in successful human xenotransplantation is HAR, which is mediated by natural anti-pig antibodies and complements in humans. The antibodies that initiate HAR recognize the Galactose- $\alpha 1,3-$ galactose $(\alpha 1,3 \mathrm{Gal})$ produced by the $\alpha 1,3-$

\footnotetext{
* Corresponding Author: M. J. Kang. Tel: +82-62-530-2113, Fax: +82-62-530-2129, E-mail: mjkang@ chonnam.ac.kr Submitted Mar. 17, 2012; Accepted May 1, 2012; Revised Aug. 2, 2012
}

galactosyltransferase (GGTA1) gene (Galili, 1993; Yang and Sykes, 2007; Le Bas-Bernardet et al., 2008). Pigs express $\alpha 1,3 \mathrm{Gal}$ on the vascular endothelium of all blood vessels. In contrast, humans, apes, and old-world monkeys do not express $\alpha 1,3 \mathrm{Gal}$ because GGTA1 was inactivated in the course of evolution and high levels of anti- $\alpha 1,3 \mathrm{Gal}$ antibody are made instead (Galili et al., 1988). To overcome HAR, GGTA1 deficient pigs ( $\alpha 1,3 \mathrm{Gal}-/-$ pig) that do not express that $\alpha 1,3 \mathrm{Gal}$ epitope were developed by somatic cell nuclear transfer using gene-targeted fetal fibroblasts (Dai et al., 2002; Lai et al., 2002; Sharma et al., 2003). Transgenic pigs were also developed to overexpress human complement regulatory proteins such as $\mathrm{hDAF}$ (CD55) (Lavitrano et al., 2002), membrane cofactor protein (MCP, CD46) (Diamond et al., 2001; Zhou et al., 2002), or protectin (CD59) (Fodor et al., 1994). When GGTA1 deficient pig hearts are transplanted into baboons, graft survival increases 2 to 6 months (Kuwaki et al., 2005). In addition, these hearts prevented HAR (Kuwaki et al., 2005). When kidneys from GGTA1 deficient pigs are transplanted into baboons, graft rejection increases 4 to $83 \mathrm{~d}$ by AHXR (Chen et al., 2005; Yamada et al., 2005). When kidneys from $\mathrm{hDAF}$ transgenic pigs with $\alpha 1,3 \mathrm{Gal}$ are transplanted into baboons or monkeys, graft survival increases 1 to $90 \mathrm{~d}$ (Baldan et al., 2004; Chen et al., 2006). Overall xenograft 
survival did not differ between GGTA1 knock-out pig organs and hDAF transgenic pig organs (Yang and Sykes, 2007). In pig-to-primate xenotranplantation, expression of transgenes on the endothelial cells is very important to immunological rejection because the endothelial cells are revealed first to various components of the recipient's immune system (Aigner et al., 2010). In addition, simultaneous expression of multi-genes, such as human complement regulatory protein (hDAF, CD46, CD59), is needed to protect from HAR and AHXR. Elimination of GGTA1 expression is also important. Production of transgenic pigs harboring multi human complement regulatory protein were produced by co-injection experiments and the genes were expressed in a nonsegregating site of the host genome using the human elongation factor1 alpha (Monoret et al., 2004), chick betaactin (Byrne et al., 1995), and ICAM2 (Cowan et al., 2003) promoter.

The development of $\alpha 1,3 \mathrm{Gal}$ deficient pigs expressing human complement regulatory proteins such as hDAF, MCP, and CD59 is necessary to overcome hyperacute rejection of pig organs transplanted into non-human primates by gene targeting technology. Gene targeting is a technique that uses homologous recombination to change and replace an endogenous gene (Clark et al., 2000). Gene targeting technology can be used to accurately place an exogenous gene in a genomic locus. The insertion of an exogenous gene using gene targeting technology makes it is possible to express an exogenous gene in a host organism using all of the gene expression regulation mechanisms of the genomic locus.

In this study, we developed a knock-in vector that expresses hDAF on the GGTA1 locus and isolated heterozygous porcine somatic cells transfected with this knock-in vector. In knock-in heterozygous cells expressing hDAF on the GGTA1 locus using the gene regulatory sequence of the GGTA1 gene, the expression of the GGTA1 gene decreased by half. However, hDAF expression was detected in knock-in heterozygous cells. Survival rate of knock-in heterozygous cells treated with human serum was higher than that of control and GGTA1 knock-out heterozygous cells.

\section{MATERIALS AND METHODS}

\section{Construction of knock-in vector}

Genomic DNA was extracted from blood of Chicago miniature pigs and used for polymerase chain reaction (PCR) amplification. The $5.4 \mathrm{~kb} 5$ ' arm fragment of GGTA1 gene was cloned by PCR amplication using forward primer with additional SalI site (GTCGACCAACACTGGATCC TTAACCCATTG) and reverse primer with additional NcoI site (CCATGGTTTTCTCCTGGGAAAAGAAAAGGA) primers. The $2.5 \mathrm{~kb} 3$ ' arm fragment of GGTA1 was cloned by PCR amplication using sense primer with additional SmaI site (CCCGGGAATGTCAAAGGAAGAGTGGTTC) and antisense primers with additional XhoI site (CTCGAGGGAACTTGCTCTTCTGTTAGAT). The hDAF gene was kindly provided by Dr. Kang in the KRIBB. SV40 polyA was cloned using pCMV-Tag1 vector (Stratagene, USA) as template by PCR using sense primer with additional XhoI site (GTCGACACTCGATCGCCCTT) and antisense primer with additional EcoRI site (GAATTCAATTTACGCGTTAA). NLS sequence was cloned using pEGFP-N3 vector (Clontech, USA) as a template by PCR using sense (GCGGCCGCGATTC GGATTCGGAGTTA) and antisense (CTCGAGCCAGC TGTGGAATG) primers. Knock-in vectors were constructed as follows: the SmaI-XhoI fragments from the GGTA1 3' arm plasmid were ligated into the SmaI-XhoI site in the pMCDT-A plasmid (Gibco BRL, USA) to produce pMCDTGT3'arm plasmid. PGK-neo plasmid was digested with BamHI enzyme, blunt-ended with Klenow, and ligated to SmaI linker. EcoRI-SmaI PGK-neo fragments were ligated into the EcoRI-SmaI site in the pBluscript KS- to produce pBKS-neo plasmid. The SalI-EcoRI SV40 polyA fragments were inserted into the SalI-EcoRI site in the pBKS-neo plasmid to produce pBSK-SV40poly-neo plasmid. The resulting SalI-SmaI fragments from pBSK-SV40poly-neo plasmid were ligated into the pMCDT-GT3'arm plasmid to produce pMCDT-polyA-neo-3'arm plasmid. To attach the NLS sequence to the GGTA1 5'arm, SalI-NcoI fragments from T-easy-GGTA1 5' arm plasmid and NotI-XhoI fragments from T-easy-NLS plasmid were ligated into the NcoI-NotI site in the T-easy vector by 3 fragment ligation. BspH1-SalI fragments from human DAF plasmid and NcoINotI fragments from NLS-GT5' arm plasmid were inserted NotI-Sall site in the T-easy vector by 3 fragment ligation to produce T-easy-NLS-GT5'arm-hDAF plasmid. Finally, to produce knock-in vector, NotI-SalI fragments from T-easyNLS-GT5'arm-hDAF plasmid were ligated into the NotISalI site in the pMCDT-GT3'arm plasmid. These knock-in vectors consist of NLS sequence, GGTA1 5' arm (5.4 kb), human DAF cDNA, SV40 poly A, neomycin resistance gene (neo) as a positive selectable marker gene, GGTA1 3 'arm $(2.5 \mathrm{~kb})$, and the diphtheria toxin A fragment (DT-A) gene as a negative selectable marker gene (Figure 1A).

\section{Culture and transfection}

Porcine ear fibroblasts were prepared from ear skin biopsies from specific pathogen-free (SPF) Minnesota miniature pigs maintained at Seoul National University (Ahn et al., 2011). The cells were cultured with culture medium (DMEM, 15\% FBS, 1×non-essential amino acids, 
A)

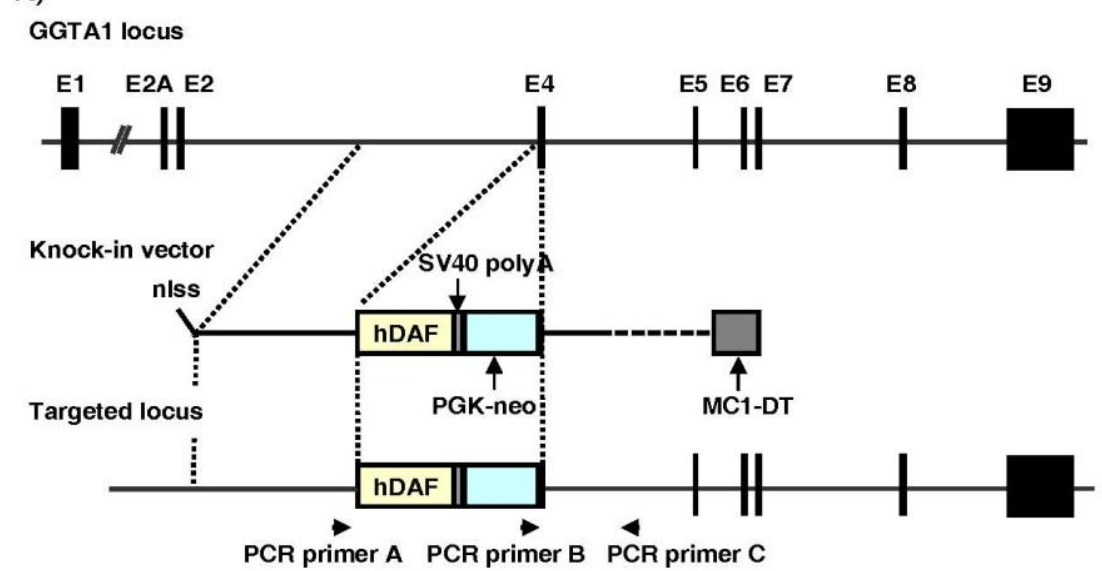

B)
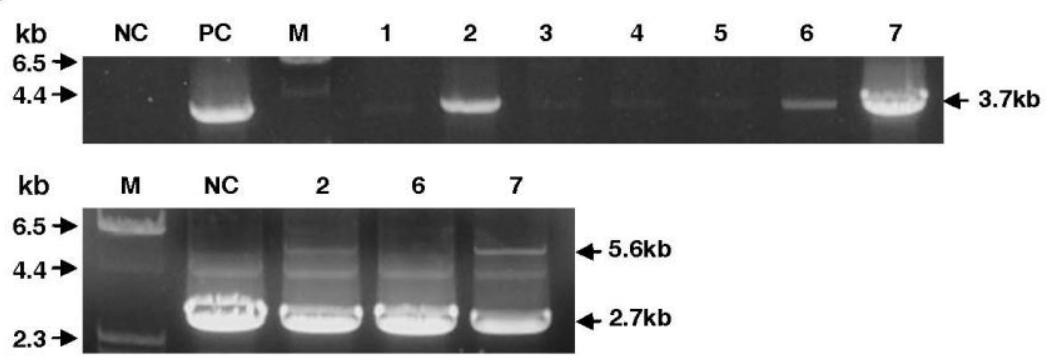

Figure 1. Gene targeting of the GGTA1 locus using knock-in vector. (A) Diagram indicating homologous recombination of knock-in vector at the porcine GGTA1 locus. The PCR primer pairs used for detection of homologous recombination are shown as primer A, B, and C. (B) Representative EtBr stained agarose gel of 1st PCR amplicons (upper panel) from primer B and C, and 2nd PCR amplicons (lower panel) from primer A and B of G418-resistant colonies selected from a transfection with linear knock-in vector. $\mathrm{M}=$ size marker $(\gamma /$ HindIII $) ; \mathrm{NC}=$ Negative control; PC = Positive control; Number = G418-resistant colonies.

$1 \times$ sodium pyruvate, $10^{-4} \mathrm{M} \beta$-mercaptoethanol, $100 \mathrm{unit} / \mathrm{ml}$ penicillin, $100 \mu \mathrm{g} / \mathrm{ml}$ streptomycin) for electroporation. The cells were trypsinized and resuspended at a concentration of $1.25 \times 10^{7}$ cells $/ \mathrm{ml}$ in F10 nutrient mixture. Four hundred microliters of the cell suspension were electroporated in a 4 $\mathrm{mm}$ cuvette using $10 \mu \mathrm{g}$ knock-in vectors with four-1 ms pulses using $400 \mathrm{~V}$ capacitive discharges by BTX Electrocell manipulator (ECM 2001, BTX, USA). After elecroporation, the cuvette was placed on ice for $10 \mathrm{~min}$. The cells in the cuvette were resuspended in $10 \mathrm{ml}$ of medium, distributed into a 48-well plate, and further cultured. After $24 \mathrm{~h}$, selection was performed for $11 \mathrm{~d}$ using $300 \mu \mathrm{g} / \mathrm{ml}$ of G418 (Gibco BRL, USA).

\section{Screening of knock-in colony}

Identification of knock-in colonies was performed by 1st PCR and 2nd PCR. For screening of G418-resistant colonies by 1 st PCR, $200 \mu \mathrm{l}$ of cell suspension from 24 -well plate were recovered by centrifugation. The cells were resuspended in $50 \mu \mathrm{l}$ of distilled water containing 0.05 $\mathrm{mg} / \mathrm{ml}$ proteinase $\mathrm{K}$ (Roche, USA). To extract genomic DNA, the cells were incubated at $55^{\circ} \mathrm{C}$ for $130 \mathrm{~min}$ and heated to $98^{\circ} \mathrm{C}$ for $10 \mathrm{~min}$ to inactive the proteinase $\mathrm{K}$. 1st
PCR was performed with $20 \mu \mathrm{l}$ genome extract, neo sense (TCGTGCTTTACGGTATCGCCGCTCCCGATT) and 3' GT antisense (TCCTCATCTAGAAATGTGGACTAA CACTGA) primers, $1 \times \mathrm{PCR}$ buffer, $0.5 \mathrm{U}$ Ex Taq polymerase (Takara, Japan), and $200 \mu \mathrm{M}$ of dNTP mixture in a total volume of $50 \mu$ l. PCR amplication was repeated for 33 cycles of $30 \mathrm{~s}$ at $94^{\circ} \mathrm{C}$ for denaturation, $30 \mathrm{~s}$ at $65^{\circ} \mathrm{C}$ for annealing, and $5 \mathrm{~min}$ at $72^{\circ} \mathrm{C}$ for extension. To identify targeted and non-targeted alleles in knock-in cells, 2nd PCR was conducted using $200 \mathrm{ng}$ of genomic DNA isolated from G418-resistence colonies, 10 pmole each of sense primer (AGGTAGAACGCACTCCTTAGCGCTCGTTGA) and 3' GT antisense (TCCTCATCTAGAAATGTGGACTAACA CTGA), $1 \times$ PCR buffer, $2.5 \mathrm{mM}$ of each dNTP, and $2.5 \mathrm{U}$ LA Taq DNA polymerase (Takara, Japan) in a total volume of $50 \mu \mathrm{l}$. PCR amplification was repeated for 33 cycles of $30 \mathrm{~s}$ at $94^{\circ} \mathrm{C}, 30 \mathrm{~s}$ at $65^{\circ} \mathrm{C}$, and $7 \mathrm{~min}$ at $72^{\circ} \mathrm{C}$. PCR products $(20 \mu \mathrm{l})$ were confirmed by electrophoresis on a $0.8 \%$ agarose gel.

\section{RT-PCR and real-time PCR}

Total RNA was isolated from normal pig cells and knock-in cells using Trizol regent (Invitrogen, Netherlands). 
Table 1. The efficiency of gene targeting at the GGTA1 locus with knock-in vector for DAF expression

\begin{tabular}{lcccc}
\hline No. of cells transfected & $\begin{array}{c}\text { No of G418 } \\
\text { resistance colonies }\end{array}$ & $\begin{array}{c}\text { No of G418 } \\
\text { colonies analyzed by PCR }\end{array}$ & \multicolumn{2}{c}{ Positive colonies } \\
\hline $5 \times 10^{6}$ & 252 & 242 & 7 & 1st PCR \\
\hline
\end{tabular}

The total RNA was then treated with DNase I, after which reverse transcription was performed at $42^{\circ} \mathrm{C}$ for $90 \mathrm{~min}$ using $5 \mu \mathrm{g}$ of total RNA, random primer, and Superscript II RNase H-Reverse transcriptase (Invitrogen, Netherlands). A $50 \mathrm{ng}$ cDNA aliquot was utilized for PCR amplification of hDAF (sense primer, CGTACAAATGTGAAGAAAGC; antisense primer, GGTACATCAATCTGACCATT), GGTA1 (sense primer, GAGTTGGAACGCAGCACCTTCCCTT; antisense primer, TATCCAGAACAAAGAACCTTCTGGG), and $\mathrm{H} 2 \mathrm{a}$ (sense primer, GAGTACCTGACCGCGGAA; antisense primer, GGCTCTCCGTCTTCTTGG). The PCR reaction mixes contained $2.5 \mathrm{U}$ Ex Taq polymerase, $1 \times \mathrm{PCR}$ buffer, $2.5 \mathrm{mM}$ of each dNTP, 10 pmole each sense and antisense primers in a total volume of $50 \mu \mathrm{l}$. PCR was performed with either GGTA1, hDAF, or H2a primers for a total 28,33 , and 28 cycles, respectively. Denaturation steps were $94^{\circ} \mathrm{C}$ for $30 \mathrm{~s}$, annealing steps were $63^{\circ} \mathrm{C}$ for $30 \mathrm{~s}$ (with GGTA1 and $\mathrm{H} 2 \mathrm{a}$ ) or $51^{\circ} \mathrm{C}$ for $30 \mathrm{~s}$ (with hDAF), and polymerization steps were $72^{\circ} \mathrm{C}$ for $40 \mathrm{~s}$ (with GGTA1) or $30 \mathrm{~s}$ (with hDAF and $\mathrm{H} 2 \mathrm{a}$ ). The PCR products were electrophoresed on $1.2 \%$ agarose gels, stained with ethidium bromide, and revealed by UV irradiation. Comparative real-time PCR was performed with a QuantiTect SYBR Green RT-PCR kit (QIAGEN, Germany) using $25 \mu \mathrm{l}$ of reaction solution containing $12.5 \mu \mathrm{l}$ of $2 \times$ QuantiTect SYBR Green PCR master mix, 40 ng of cDNA, and $120 \mathrm{nM}$ primers (sense primer, GAGTTGGAACGCA GCACCTTCCCTT; antisense primer, TATCCAGAACAAA GAACCTTCTGGG). Each reaction was conducted in triplicate and run in a Roter Gene 2000 system (Cobett Research). The thermal cycling conditions were as follows: $95^{\circ} \mathrm{C}$ for $15 \mathrm{~min}$, followed by 45 cycles of denaturation at $94^{\circ} \mathrm{C}$ for $15 \mathrm{~s}$, annealing at $50^{\circ} \mathrm{C}$ for $30 \mathrm{~s}$, and extension at $72^{\circ} \mathrm{C}$ for $20 \mathrm{~s}$. The mRNA levels were corrected using the transcription level of the $\mathrm{H} 2 \mathrm{a}$ gene as an internal standard. All reactions were performed in triplicate and threshold cycle $(\mathrm{Ct})$ values were normalized to $\mathrm{H} 2$ a gene. The change in gene expression was calculated based on the ratio of expression levels of knock-in somatic cells to the expression level of control somatic cells (Guo et al., 2008).

\section{Complement-mediated lysis}

Control somatic cells, GGTA1 knock-out heterozygous cells, and knock-in heterozygous cells expressing hDAF on GGTA1 locus $\left(4 \times 10^{3}\right.$ cells $)$ were inoculated in a 96 well plate and cultured to $90 \%$ confluent. GGTA1 knock-out heterozygous cells (GT-KO) were previously isolated by transfection of GGTA1 knock-out vector into ear fibroblast from miniature pigs (Ahn et al., 2011). The cells were washed with PBS and cultured with $100 \%$ human complement serum (Innovative, USA) for $2 \mathrm{~h}$. The serum was replaced with fresh culture medium and cultured for $2 \mathrm{~h}$. Cytotoxicity was detected using CCK-8 kits according to manufacturer's instruction (Dojindo, Japan). All experiments were performed in triplicate. The ratio of cell viability was calculated based on the ratio of viability of cells treated with HCS to the viability of cells treated with FBS.

\section{RESULTS}

\section{Gene targeting of the GGTA1 locus using knock-in vector to express hDAF gene}

Primary porcine ear fibroblast cells were used for transfection with knock-in vector. G418-resistant colonies were screened by 3' PCR (1st PCR) with neo sense (primer $\mathrm{B}$, a sequence from the 3' end of neo gene) and 3' GT antisense (primer $\mathrm{C}$, a sequence from the center of intron 4 in sequence located outside the 3 ' recombination arm) as forward and reverse primers (Figure 1A). Thus, only through successful targeting at the GGTA1 locus would the expected $3.7 \mathrm{~kb}$ PCR products be obtained. From the transfection of $5 \times 10^{6}$ cells, 252 G418-resistant colonies were picked, of which 7 were positive for GGTA1 gene disruption in the initial 3' PCR screen (Table 1). Figure 1B (upper panel) shows the 3' PCR results for representative group of G418-colonies. Colonies 2, 6, and 7 showed a strong band and other G418-colonies $(1,3,4,5)$ presented a weak band. Therefore, to further confirm successful targeting at the GGTA1 locus, we carried out an LA-PCR (2nd PCR) experiment encompassing the entire targeted region. The LA-PCR covered the $2.7 \mathrm{~kb}$ GGTA1 genomic sequence from intron 3 to intron 4 , with both primers (primer A and primer C) located outside of the recombination region (Figure 1A). The control somatic cells showed only the endogenous $2.7 \mathrm{~kb}$ band from wild-type GGTA1 locus (Figure 1B lower panel). In contrast, two colonies ( 2 and 7) showed both the $2.7 \mathrm{~kb}$ endogenous band and a new band of $5.6 \mathrm{~kb}$, the size expected for targeted insertion of the hDAF and PGK-neo cassette into the GGTA1 locus. As some 3' PCR-positive signal may come from PCR artifacts, the LA-PCR assay is crucial to confirm successful knock-in events. Efficiency of gene targeting may be included in Table 1 . 
A)

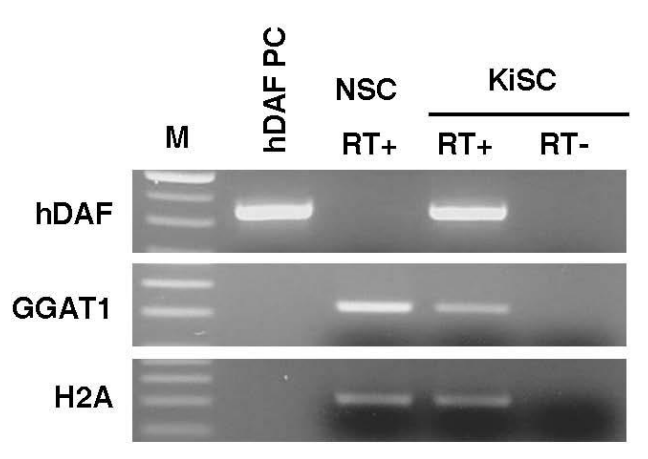

B)

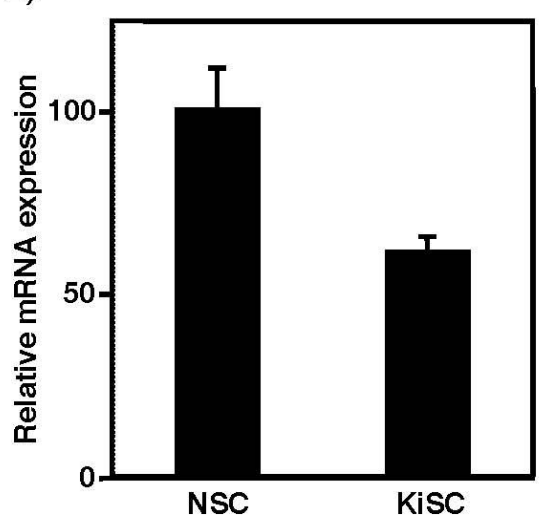

Figure 2. mRNA expression of hDAF and GGTA1 gene in knock-in heterozygous cells. A) hDAF and GGTA1 expression by RT-PCR. Total RNA isolated from normal pig somatic cell (NSC) and knock-in somatic cell (KiSC) were used for cDNA synthesis by reverse transcription and the mRNA expression of hDAF and GGTA1 gene, respectively, were detected with specific primer. hDAF plasmid (hDAF PC) was used as positive control for only detection of hDAF expression. A negative control (RT-) lacking cDNA did not generate an RT-PCR product. M is 100 bp ladder. B) GGTA1 expression in the NSC and KiSC by real-time PCR.

\section{Expression of hDAF gene using GGTA1 gene regulatory sequence}

Because the knock-in vector contained the hDAF gene at the ATG site of the GGTA1 gene, we analyzed the mRNA expression of the hDAF and GGTA1 genes by RT-PCR using total RNA isolated from knock-in heterozygous cells and control somatic cells. As shown Figure 2A, mRNA expression of hDAF gene was detected in the knock-in heterozygous cells but not in the control somatic cells. However, because the knock-in vector is integrated into one allele of the GGTA1 gene, one allele of the GGTA1 gene was not expressed in mRNA. In this study, GGTA1 gene expression decreased by half compared with the expression in control somatic cells that were not transfected with the knock-in vector in the RT-PCR (Figure 2A) and real-time PCR (Figure 2B). These results indicated that the expression of hDAF gene was regulated by the gene regulatory sequence of one GGTA1 allele.

\section{Complement-mediated lysis of knock-in cells with human complement serum}

The resistance for immune reaction by complement in human serum was tested in knock-in heterozygous cells. These cells have one mutant allele for GGTA1 gene that was disrupted by knock-in vector one and one normal allele. The cells expressed the hDAF gene using gene regulatory sequences including the promoter and enhancer of the GGTA1 gene. As shown in Figure 3, knock-in heterozygous cells were more resistant to lysis than control cells. Survival rate of knock-in heterozygous cells treated with human serum for $2 \mathrm{~h}$ was $35.4 \%$ when compared with the knock-in heterozygous cells treated with FBS (100\%). However, survival in control and GGTA1 knock-out heterozygous cells were $20.7 \%$ and $25.9 \%$, respectively, in the human serum.

\section{DISCUSSION}

Homologous recombination of a foreign DNA fragment is a very difficult process in the domestic animal cells compare with mouse ES cells. In this study, we isolated 2 colonies from $252 \mathrm{G} 418$ resistance colonies. The targeting efficiency was only $0.8 \%$. It has previously been reported that efficiency of targeting on the GGTA1 gene varied from 0 to $9.3 \%$ (Klumiuk et al., 2010). Lai et al reported 5\% targeting efficiency using neo gene with a positive selection marker and a $21 \mathrm{~kb}$ homologous sequence (Lai et al., 2002;

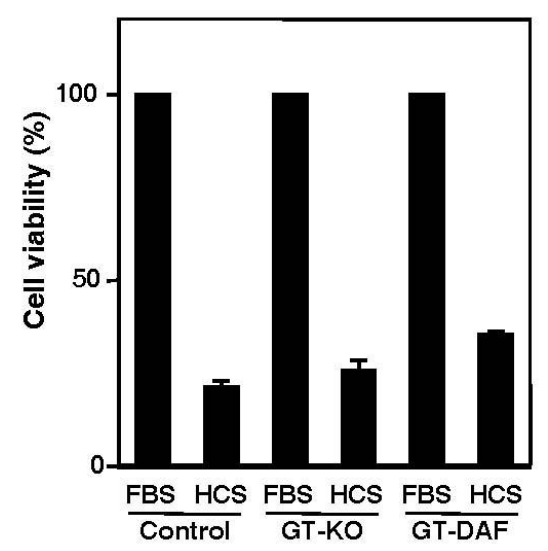

Figure 3. Complement mediated cell lysis in knock-in heterozygous cells. GGTA1 knock-out heterozygous cells (GT$\mathrm{KO})$ were previously isolated by transfection of GGTA1 knockout vector into ear fibroblast from miniature pigs. GT-KO is GGTA1 knock-out heterozygous cells and GT-DAF is knock-in heterozygous cells expressing hDAF on GGTA1 locus. The viability in cells treated with $100 \%$ human complement serum is compared with $100 \%$ survival in the cells treated with $100 \%$ FBS. FBS $=$ Fetal bovine serum; HCS $=$ Human complement serum. 
Klumiuk et al., 2010). But Dai et al. obtained 0.5 to $2.3 \%$ targeting efficiency (Dai et al., 2002; Klumiuk et al., 2010) using a $9.31 \mathrm{~kb}$ homologous sequence and methods similar to Lai et al. High targeting efficiency $(9.3 \%)$ was reported using a $10.2 \mathrm{~kb}$ homologous sequence and promoter trap that expressed neo gene by GGTA1 gene promoter. In this study, as shown Figure 1, we constructed a knock-in vector consisting of $5.4 \mathrm{~kb} \mathrm{5'}$ arm and a $2.5 \mathrm{~kb} \mathrm{3'}$ arm. This result indicated that targeting efficiency is low because knock-in vectors consist of a $7.9 \mathrm{~kb}$ homologous sequence.

In transgenic animals developed by pronuclear microinjection, transgenes were usually integrated in only one site with multiple copies. Expression of transgenes was usually low because the promoter is not expected to work (Houdebine, 2000). Here, we inserted hDAF cDNA into the ATG site of the GGTA1 gene so that the hDAF gene was expressed by gene regulatory sequences including the promoter and enhancer of the GGTA1 gene. Therefore, we thought that the hDAF gene in these knock-in somatic cells is probably expressed at the same level as the GGTA1 gene.

Human DAF regulates the complement system on the cell surface and overexpression of hDAF genes in pig cells provided effective protection against HAR in xenotransplantation (Baldan et al., 2004; Chen et al., 2006; Sprangers et al., 2008). Expression of hDAF gene in transgenic pigs produced by random integration was unstable depending on the individual transgenic pig (Lavitrano et al., 2002). The GGTA1 gene was expressed on endothelial cells and produced the $\alpha 1,3 \mathrm{Gal}$ carbohydrate on the cell surface (Galili et al., 1988; Galili, 1993; Yang and Sykes, 2007; Le Bas-Bernardet et al., 2008). Expression of human complement regulatory protein, such as hDAF, CD46, and CD59, on endothelial cells was critical for protection against HAR in xenotransplantation because the endothelial cells are first exposed to the various components of the recipient's immune system (Aigner et al., 2010). However, $\alpha 1,3 \mathrm{Gal}$ carbohydrate was detected at low levels in the knock-out pig cells of GGTA1 gene (Sharma et al., 2003; Yang and Sykes, 2007; Sprangers et al., 2008). $\alpha 1,3 \mathrm{Gal}$ carbohydrates were expressed by iGb3 synthase in rodents and pigs (Yang and Sykes, 2007; Sprangers et al., 2008). These results indicated that low levels of Gal antigen in the knock-out pig cells of GGTA1 gene probably produced HAR in the pig-to-nonhuman xenotransplantation. Non- $\alpha$ Gal antigens were detected in knock-out pig cells of GGTA1 gene. Non- $\alpha \mathrm{Gal}$ antigens and $\alpha \mathrm{Gal}$ antigens were induced in acute humoral xenograft rejection (AHXR) in the GGTA1 knock-out pig cells (Yang and Sykes, 2007; Sprangers et al., 2008). Therefore, development of GGTA1 knock-out pigs that express hDAF genes by the knock-in system is important in pig-to-nonhuman xenotransplantation. In this study, hDAF mRNA was expressed by GGTA1 gene regulatory sequence on the
GGTA1 gene locus. Our results indicated that co-regulation of the GGTA1 and hDAF genes are more effective in limiting complement-dependent cytolysis than either protein expressed alone on the surface of host cells.

Peripheral blood mononuclear cells from hDAF transgenic pigs had higher survival rates when treated with complement in human serum (Lavitrano et al., 2002). Transgenic pigs expressing the hDAF gene were effectively protected against HAR in xenotransplantation by regulation of the complement system on the cell surface (Baldan et al., 2004; Chen et al., 2006; Sprangers et al., 2008). In the present study, we demonstrated that overexpression of hDAF gene in the GGTA1 locus using knock-in vector protected cells from lysis in human serum compared with GGTA1 knock-out heterozygous and control cells. Although these knock-in heterozygous cells have one normal allele GGTA1 gene, knock-in heterozygous cells expressed hDAF gene using the regulatory sequences of the GGTA1 gene. These results suggest that knock-in heterozygous cells may afford more effective protection against cytotoxicity of human serum than GGTA1 knockout or hDAF transgenic pigs. However, to our knowledge, this is first attempt to use this strategy to express transgenes (hDAF) using the GGTA1 gene regulatory sequence in porcine somatic cells.

In this study, we constructed knock-in vectors for expression of hDAF genes on the GGTA1 locus and isolated knock-in heterozygous cells that introduced these knock-in vectors. Knock-in heterozygous cells expressed the hDAF gene and down-regulated the expression of the GGTA1 gene. Moreover, knock-in heterozygous cells were better protected from lysis by complements in human serum than were GGTA1 knock-out heterozygous and control cells. These results indicated that the simultaneous expression of the hDAF gene by the gene regulatory sequence of the GGTA1 gene and knock-out of GGTA1 gene is more effective protection from HAR in pig-to-nonhuman xenotransplantation. Knock-in heterozygous cells may be used in the production of transgenic pigs that simultaneously disrupt the GGTA1 allele and insert the hDAF gene.

\section{ACKNOWLEDGEMENTS}

This study was supported by a grant from the Korea Biotech R\&D Group of Next-Generation Growth Engine Project (F104AD01000208A040100211) and Woo JangChoon projects from the Rural Development Administration, Republic of Korea (PJ007849).

\section{REFERENCES}

Ahn, K. S., Y. J. Kim, M. Kim, B. H. Lee, S. Y. Heo, M. J. Kang, Y. 
K. Kang, J. W. Lee, K. K. Lee, J. H. Kim, W. G. Nho, S. S. Hwang, J. S. Woo, J. K. Park, S. B. Park and H. Shim. 2011. Resurrection of an alpha-1,3-galactosyltransferase genetargeted miniature pig by recloning using postmortem ear skin fibroblast. Theriogenology 75:933-939.

Aigner, B., N. Klymiuk and E. Wolf. 2010. Transgenic pig for xenotransplantation: selection of promoter sequences for reliable transgene expression. Curr. Opin. Organ. Transplant. 15:201-206.

Baldan, N., P. Rigotti, F. Calabrese, R. Cadrobbi, A. Dedja, I. Iacopetti, M. Boldrin, M. Seveso, L. Dall'Olmo, L. Frison, G. De Benedictis, D. Bernardini, G. Thiene, E. Cozzi and E. Ancona. 2004. Ureteral stenosis in HDAF pig-to-primate renal xenotransplantation: a phenomenon related to immunological events? Am. J. Transplant. 4:475-481.

Byrne, G. W., K. R. McCurry, D. Kagan, C. Quinn, M. J. Martin, J. L. Platt and J. S. Logan. 1995. Protection of xenogenic cardiac endothelium from human complement by expression of CD59 or DAF in transgenic mice. Transplantation 60:1149-1156.

Chen, G., H. Qian, T. Starzl, H. Sun, B. Garcia, X. Wang, Y. Wise, Y. Liu, Y. Xiang, L. Copeman, W. Liu, A. Jevnikar, W. Wall, D. K. Cooper, N. Murase, Y. Dai, W. Wang, Y. Xiong, D. J. White and R. Zhong. 2005. Acute rejection is associated with antibody to non-Gal antigens in baboons using Gal-knockout pig kidneys. Nat. Med. 11:1295-1298.

Chen, G., H. Sun, H. Yang, D. Kubelik, B. Garcia, Y. Luo, Y. Xiang, A. Qian, L. Copeman, W. Liu, C. J. Cardella, W. Wang, Y. Xiong, W. Wall, D. J. White and R. Zhong. 2006. The role of anti-non-Gal antgibody in the development of acute humoral xenograft rejection of hDAF transgenic porcine kidneys in baboons receiving anti-Gal antibody neutralization therapy. Transplantation 81:273-283.

Clark, A. J., S. Burl, C. Denning and P. Dickinson. 2000. Gene targeting in liverstock: a preview. Transgenic Res. 9:263-275.

Cowan, P. J., T. A. Shinkel, N. Fisicaro, J. W. Godwin, C. Bernabéu, N. Almendro, C. Rius, A. J. Lonie, M. B. Nottle, P. L. Wigley, K. Paizis, M. J. Pearse and A. J. d'Apice. 2003. Targeting gene expression to endothelium in transgenic animals: a comparison of the human ICAM-2, PECAM-1 and endoglin promoters. Xenotransplantion 10:223-231.

Dai, Y., T. D. Vaught, J. Boone, S. H. Chen, C. J. Phelps, S. Ball, J. A. Monahan, P. M. Jobst, K. J. McCreath, A. E. Lamborn, J. L. Cowell-Lucero, K. D. Wells, A. Colman, I. A. Polejaeva and D. L. Ayares. 2002. Targeted disruption of the alpha1,3galactosyltransferase gene in cloned pigs. Nat. Biotechnol. 20: 251-255.

Diamond, L. E., C. M. Quinn, M. J. Martin, J. Lawson, J. L. Platt and J. S. Logan. 2001. A human CD46 transgenic pig model system for the study of discordant xenotransplantation. Transplantation 71:132-142.

Fodor, W. L., B. L. Williams, L. A. Matis, J. A. Mardri, S. A. Rollins, J. W. Knight, W. Velander and S. P. Squinto. 1994. Expression of a functional human complement inhibitor in a transgenic pig as a model for the prevention of xenogeneic hyperacute organ rejection. Proc. Natl. Acad. Sci. USA. 91: 11153-11157.

Galili, U., S. B. Shohet, E. Kobrin, C. L. M. Stults and B. A. Macher. 1988. Man, apes, and old world monkeys differ from other mammals in the expression of $\alpha$-galactosyl epitopes on nucleated cells. J. Biol. Chem. 263:17755-17762.

Galili, U. 1993. Interaction of the natural anti-Gal antibody with alpha-galactosyl epitopes: a major obstacle for xenotransplantation in human. Immunol. Today 14:480-482.

Guo, W., S. H. Wang, H. J. Cao, K. Xu, J. Zhang, Z. L. Du, W. Lu, J. D. Feng, N. Li, C. H. Wu and L. Zhang. 2008. Gene microarray analysis for porcine adipose tissue: comparison of gene expression between Chinese Xiang pig and Large White. Asian-Aust. J. Anim. Sci. 21:11-18.

Houdebine, L. M. 2000. Transgenic animal bioreactors. Transgenic Res. 9:305-320.

Klumiuk, N., B. Aigner, G. Brem and E. Wolf. 2010. Genetic modification of pigs as organ donors for xenotransplantation. Mol. Reprod. Dev. 77:209-221.

Kuwaki, K., Y. L. Tseng, F. J. Dor, A. Shimizu, S. L. Houser, T. M. Sanderson, C. J. Lancos, D. D. Prabharasuth, J. Cheng, K. Moran, Y. Hisashi, N. Mueller, K. Yamada, J. L. Greenstein, R. J. Hawley, C. Patience, M. Awwad, J. A. Fishman, S. C. Robson, H. J. Schuurman, D. H. Sachs and D. K. Cooper. 2005. Heart transplantation in baboons using alpha 1,3galactosyltransferase gene-knockout pigs as donors: initial experience. Nat. Med. 11:29-31.

Lai, L., D. Kolber-Simonds, K. W. Park, H. T. Cheong, J. L. Greenstein, G. S. Im, M. Samuel, A. Bonk, A. Rieke, B. N. Day, C. N. Murphy, D. B. Carter, R. J. Hawley and R. S. Prather. 2002. Production of alpha-1,3-galactosyltransferase knockout pigs by nuclear transfer cloning. Science 295:1089-1092.

Lavitrano, M., M. L. Bacci, M. Forni, D. Lazzereschi, C. Di Stefano, D. Fioretti, P. Giancotti, G. Marfé, L. Pucci, L. Renzi, H. Wang, A. Stoppacciaro, G. Stassi, M. Sargiacomo, P. Sinibaldi, V. Turchi, R. Giovannoni, G. Della Casa, E. Seren and G. Rossi. 2002. Efficient production by sperm-mediated gene transfer of human decay accelerating factor (hDAF) transgenic pigs for xenotransplantation. Proc. Natl. Acad. Sci. USA. 99:14230-14235.

Le Bas-Bernardet, S., I. Anegon and G. Blancho. 2008. Progress and prospects: genetic engineering in xenotransplantation. Gene Ther. 15:1247-1256.

Monoret, S., M. Plat, G. Blancho, F. Martinat-Botte, P. Bernard, G. Karam, L. Tesson, K. Renaudin, P. Guillouet, B. Weill, C. Chereau, L. M. Houdebine, J. P. Soulillou, M. Tergui and I. Anegon. 2004. Characterization of human CD55 and CD59 transgenic pig and kidney xenotransplantation in the pig-tobaboon combination. Transplantation 77:1468-1471.

Sharma, A., B. Naziruddin, C. Cui, M. J. Martin, H. Xu, H. Wan, Y. Lei, C. Harrison, J. Yin, J. Okabe, C. Mathews, A. Stark, C. S. Adams, J. Houtz, B. S. Wiseman, G. W. Byrne and J. S. Logan. 2003. Pig cells that lack the gene for alpha 1-3 galactosyltransferase express low levels of the gal antigen. Transplantation 75:430-436.

Sprangers, B., M. Waer and A. D. Billiau. 2008. Xenotransplantation: Where are we in 2008 ? Kidney Int. 74: 14-21.

Yamada, K., K. Yazawa, A. Shimizu, T. Iwanaga, Y. Hisashi, M. Nuhn, P. O'Malley, S. Nobori, P. A. Vagefi, C. Patience, J. Fishman, D. K. Cooper, R. J. Hawley, J. Greenstein, H. J. Schuurman, M. Awwad, M. Sykes and D. H. Sachs. 2005. 
Marked prolongation of porcine renal xenograft survival in baboons through the use of alpha 1,3-galactosyltransferase gene-knockout donors and the cotransplantation of vascularized thymic tissue. Nat. Med. 11:32-34.

Yang, Y. G. and M. Sykes. 2007. Xenotransplantation: current status and a perspective on the future. Nat. Rev. Immunol. 7: 519-531.
Ye, Y., M. Niekrasz, S. Kosanke, R. Welsh, H. E. Jordan, J. C. Fox, W. C. Edwards, C. Maxwell and D. K. Cooper. 1994. The pig as a potential organ donor for man. A study of potentially transferable disease from donor pig to recipient man. Transplantation 57:694-703.

Zhou, C. Y., E. McInnes, N. Parsons, G. Langford, R. Lancaster, A. Richards, G. Pino-Chavez, G. Dos Santos Cruz, L. Copeman, C. Carrington and S. Thompson. 2002. Production and characterization of a pig line transgenic for human membrane cofactor protein. Xenotransplantation 9:183-190. 